\section{(6) OPEN ACCESS}

\title{
Trichomonas vaginalis infection is uncommon in the British general population: implications for clinical testing and public health screening
}

\author{
Nigel Field, ${ }^{1,2}$ Soazig Clifton, ${ }^{1}$ Sarah Alexander, ${ }^{3}$ Catherine A Ison, ${ }^{3}$ \\ Rumena Khanom, ${ }^{3}$ Pamela Saunders, ${ }^{3}$ Gwenda Hughes, ${ }^{2}$ Laura Heath, ${ }^{1}$ \\ Simon Beddows, ${ }^{4}$ Catherine H Mercer, ${ }^{1}$ Clare Tanton, ${ }^{1}$ Anne M Johnson, ${ }^{1}$ \\ Pam Sonnenberg ${ }^{1}$
}

\begin{abstract}
- Additional material is published online only. To view please visit the journal online (http://dx.doi.org/10.1136/ sextrans-2016-052660).
\end{abstract}

${ }^{1}$ Research Department of Infection and Population Health, University College London, London, UK

${ }^{2}$ Public Health England, National Centre for Infectious Disease Surveillance and Control (CIDSC), London, UK

${ }^{3}$ Sexually Transmitted Bacteria Reference Unit, Microbiological Services, Public Health England, London, UK

${ }^{4}$ Virus Reference Department, Public Health England, London, UK

\section{Correspondence to} Dr Nigel Field, Research Department of Infection and Population Health, University College London, London WC1E 6JB, UK; Nigel.field@ucl.ac.uk

Received 8 April 2016 Revised 18 August 2016 Accepted 27 August 2016 Published Online First 29 September 2016
Check for updates

To cite: Field $\mathrm{N}$

Clifton S, Alexander S,

et al. Sex Transm Infect

2018:94:226-229.

\section{ABSTRACT}

Introduction Variable use of new molecular assays, asymptomatic infections and a lack of population data mean that the population burden of Trichomonas vaginalis is uncertain. We investigated the age-specific prevalence of $T$. vaginalis within the sexually active British general population to inform testing strategies. Methods Britain's third National Survey of Sexual Attitudes and Lifestyle (Natsal-3) is a probability sample survey of 15162 individuals aged 16-74 years, undertaken during 2010-2012. Urine from 4386 participants aged 16-44 years reporting $\geq 1$ lifetime sexual partner was tested for $T$. vaginalis using in-house real-time PCR.

Results Urinary $T$. vaginalis was detected in seven women and no men providing urine samples, giving a weighted prevalence estimate of $0.3 \%(95 \% \mathrm{Cl} 0.1 \%$ to $0.5 \%$ ) in sexually experienced women aged $16-$ 44 years. Of the seven women with $T$. vaginalis detected, four were of black or mixed ethnicity (prevalence $2.7 \%(0.9 \%$ to $7.7 \%)$ in this group) and five reported recent partners of black or mixed ethnicity. Six of the women reported symptoms, and five reported sexual health clinic attendance in the past 5 years (prevalence in those reporting clinic attendance: 1.0\% $(0.4 \%$ to $2.3 \%))$. The prevalence of a self-reported history of $T$. vaginalis (past 5 years) was $0.1 \%(0.0 \%$ to $0.2 \%$ ) in women and $0.0 \%(0.0 \%$ to $0.2 \%)$ in men aged $16-44$ years.

Conclusions Our British population prevalence estimates indicate that $T$. vaginalis is a rare infection. These data support policies that restrict asymptomatic screening for $T$. vaginalis and suggest deployment of molecular tests should be focused within clinical settings and guided by symptoms and local demography.

\section{INTRODUCTION}

Trichomonas vaginalis is a sexually transmitted protozoan, which adheres to mucous membranes of the vagina and male urethra to cause trichomoniasis. Globally, T. vaginalis is the single most prevalent non-viral STI. Indeed, the WHO estimated that more than 270 million cases occurred in 2008, greater than the combined total for chlamydia and gonorrhoea. ${ }^{1}$ However, T. vaginalis diagnosis is relatively rare in the UK, with around 6000 cases reported each year, compared with over 200000 chlamydia cases. ${ }^{2}{ }^{3}$

National STI surveillance data in England show that over $90 \%$ of diagnosed T. vaginalis cases occur in women, ${ }^{2}{ }^{3}$ a gender disparity attributed to more rapid spontaneous clearance of infection in men. Between 2009 and 2011, just under half of T. vaginalis diagnoses were in women of white ethnicity (in whom the rate was 10.7/100 000 population), but the rate of $T$. vaginalis diagnoses was much higher in black Caribbean women (329.6/100 000) and women of other black ethnicities (498.4/100 000), and much lower in men (33.9/100 000 in black Caribbean men and 0.6/ 100000 in white men). ${ }^{2}$ However, diagnosis data are limited for a number of reasons, including that asymptomatic individuals may not seek healthcare, so the extent to which there might be a pool of undiagnosed infection in the wider population is unknown.

The BASHH 2014 guidelines recommend testing women according to clinical signs and symptoms, and men with persistent urethritis and/or who are contacts of individuals diagnosed with $T$. vaginalis. ${ }^{4}$ Widespread screening for T. vaginalis was previously limited because of a reliance on diagnostic assays, such as culture or wet mounts, which lack sensitivity and are time consuming. However, molecular assays with enhanced sensitivity are now readily available, either commercially or in-house, raising important questions about deployment of such tests for diagnostic and screening purposes.

The third National Survey of Sexual Attitudes and Lifestyles (Natsal-3) is a probability sample survey, which included urine testing and reported history of diagnoses to estimate the prevalence for a range of STIs. ${ }^{5}$ Natsal-3 used molecular assays for T. vaginalis to enable description of the age-specific and gender-specific prevalence of $T$. vaginalis within the sexually active British general population to inform clinical practice and public health policy.

\section{METHODS}

Participants and survey procedures

Natsal-3 was a stratified probability sample survey of 15162 men and women aged 16-74 years in Britain who were interviewed during 2010$2012 .^{6}{ }^{7}$ The estimated overall response rate was 
$57.7 \%$, and the cooperation rate was $65.8 \%$ (of all eligible addresses contacted). Participants were interviewed in their own homes using computer-assisted personal interview and computer-assisted self-interview (CASI). The CASI included questions about participants' sexual behaviour, their history of being diagnosed with STIs by a healthcare professional and their experience of genital symptoms associated with STIs in the month before interview. After the interview, we invited a sample of participants aged 16-44 years to provide urine for STI testing. Full methodological details have been described elsewhere. ${ }^{5-7}$

\section{Laboratory methods}

In 2013, we undertook anonymous testing for T. vaginalis, without return of results, on DNA extracts taken from urine samples where there was sufficient sample (4482 out of 4550 participants) and where participants had provided consent for storage (4386 out of 4482 participants). All DNA extracts were screened using a modified primary RT-PCR that detects a 92-bp repeat-region fragment of T. vaginalis $\mathrm{DNA},{ }^{89}$ and samples that generated a positive or equivocal screening result were retested with a secondary RT-PCR, which targets a conserved portion of the $T$. vaginalis $\beta$-tubulin gene. ${ }^{9}{ }^{10}$ A confirmed positive result was deemed to be one where the first RT-PCR was positive or equivocal and the second RT-PCR was positive.

\section{Statistical analysis}

Prevalence estimates with 95\% CIs in women and men are reported by age group for $T$. vaginalis detected in urine, and self-reported T. vaginalis diagnoses over the lifetime and in the past 5 years. Survey analyses were done in Stata V.13 accounting for sample stratification, clustering and weighting. Analyses were additionally weighted for unequal urine selection probabilities and differential urine sample response. ${ }^{5-7}$

\section{RESULTS}

Urinary T. vaginalis test results were available from 4386 sexually active participants (2559 women; 1827 men; 54.5\% of all eligible participants) aged 16-44 years. The primary screening test detected T. vaginalis DNA in seven samples, all of which were confirmed with the secondary test. All seven samples were from women (there were no positive tests in men), giving a weighted prevalence estimate of $0.3 \%$ (95\% CI $0.1 \%$ to $0.5 \%$ ) in women aged 16-44 years (table 1). The prevalence of T. vaginalis in women decreased with age group, with the highest prevalence $(0.6 \%(0.2 \%$ to $1.7 \%))$ in those aged $16-24$ years. Two women with $T$. vaginalis were coinfected with chlamydia, and two had at least one human papilloma virus-type detected; none of the women had Neisseria gonorrhoeae, HIV or Mycoplasma genitalium detected. ${ }^{5} \mathrm{w} 1 \mathrm{w} 2$
Although small numbers prevent detailed characterisation of cases, we observed that four of the seven women were of black or mixed ethnic origin, giving a weighted prevalence of $2.7 \%$ $(0.9 \%$ to $7.7 \%)$ in this broad ethnicity group. All seven women reported at least one opposite sex partner in the past 5 years. The four women of black or mixed ethnicity and one white woman reported partners who were of black, black British or mixed ethnicity. Five of the women reported attending a sexual health clinic in the past 5 years (for three, this was in the past year), giving an estimated weighted prevalence of $1.0 \%(0.4 \%$ to $2.3 \%$ ) among clinic attendees (past 5 years). Six of the women reported symptoms (abnormal or odorous vaginal discharge, or lower abdominal, or pelvic pain) in the month before interview. None reported a previous diagnosis of T. vaginalis.

Of 13658 Natsal participants aged 16-74 years who reported at least one lifetime partner, $0.5 \%(0.3 \%$ to $0.7 \%)$ of women and $0.0 \%(0.0 \%$ to $0.2 \%)$ of men reported a T. vaginalis diagnosis in their lifetime (corresponding to 36 women and 3 men) (table 2). Among women, reported lifetime diagnosis of T. vaginalis was more common in those aged $45-74$ years $(0.8 \%$ $(0.5 \%$ to $1.2 \%)$ compared with those aged $16-44$ years $(0.2 \%$ $(0.1 \%$ to $0.4 \%) ; \mathrm{p}=0.0018)$. However, diagnosis in the past 5 years was only reported by younger people (six women and two men), with an estimated prevalence in those aged 1644 years of $0.1 \%(0.0 \%$ to $0.2 \%)$ in women and $0.0 \%(0.0 \%$ to $0.2 \%)$ in men.

\section{DISCUSSION}

This study provides the first population-based prevalence estimates for T. vaginalis in the British general population and indicates that $T$. vaginalis is an uncommon infection. A molecular assay with confirmatory testing was used, and we detected T. vaginalis in only a small number of women in a large sample, which was broadly representative of the sexually active general population. All cases except two were in women of Black or mixed ethnicity, or reported recent partners of Black or mixed ethnicity, and most had symptoms consistent with infection. Most had recently attended a sexual health clinic. These data are supported by our finding that the prevalence of reported T. vaginalis diagnosis in the past 5 years in those aged 1644 year was also very low.

In this cross-sectional study, the use of urine, which is a suboptimal specimen for the detection of $T$. vaginalis, particularly in men, might have led to underestimation of prevalence. ${ }^{\mathrm{w} 3} \mathrm{w}^{4}$ DNA extracts were stored for up to 3 years before testing, introducing a small risk of degradation, which might have reduced assay sensitivity. While the size and representative nature of the sample are important strengths of this study, Natsal-3 did not include an ethnic boost, and the total number of non-white participants was relatively small. This meant that subanalyses were

Table 1 Prevalence of $T$. vaginalis in urine in participants aged 16-44 years, by age group and gender

\begin{tabular}{|c|c|c|c|c|c|c|c|c|}
\hline & \multicolumn{2}{|l|}{ Women } & \multicolumn{2}{|l|}{ Men } & \multicolumn{2}{|c|}{$\begin{array}{l}\text { Denominator } \\
\text { women }\end{array}$} & \multicolumn{2}{|c|}{$\begin{array}{l}\text { Denominator } \\
\text { men }\end{array}$} \\
\hline & Per cent & $\mathrm{Cl}$ & Per cent & $\mathrm{Cl}$ & Unwt & Wt & Unwt & Wt \\
\hline $16-24$ & 0.6 & $(0.2 \%$ to $1.7 \%)$ & 0 & & 958 & 576 & 818 & 604 \\
\hline $25-34$ & 0.3 & (0.1\% to $1.0 \%)$ & 0 & & 1097 & 774 & 668 & 778 \\
\hline $35-44$ & 0.0 & & 0 & & 504 & 838 & 341 & 809 \\
\hline Total & 0.3 & ( $0.1 \%$ to $0.5 \%)$ & 0 & & 2559 & 2188 & 1827 & 2191 \\
\hline
\end{tabular}


Table 2 Self-reported history of $T$. vaginalis in participants aged 16-74 years, by age group, gender and timeframe

\begin{tabular}{|c|c|c|c|c|c|c|c|c|}
\hline & \multicolumn{2}{|l|}{ Women } & \multicolumn{2}{|l|}{ Men } & \multicolumn{2}{|c|}{$\begin{array}{l}\text { Denominator } \\
\text { women }\end{array}$} & \multicolumn{2}{|c|}{$\begin{array}{l}\text { Denominator } \\
\text { men }\end{array}$} \\
\hline & Per cent & $\mathrm{Cl}$ & Per cent & $\mathrm{Cl}$ & Unwt & Wt & Unwt & Wt \\
\hline \multicolumn{9}{|l|}{ Lifetime diagnoses } \\
\hline $16-24$ & 0.1 & $(0.0 \%$ to $0.4 \%)$ & 0.1 & $(0.0 \%$ to $0.8 \%)$ & 1726 & 962 & 1363 & 990 \\
\hline $25-34$ & 0.3 & $(0.1 \%$ to $0.6 \%)$ & 0.1 & $(0.0 \%$ to $0.4 \%)$ & 2362 & 1304 & 1431 & 1281 \\
\hline $35-44$ & 0.3 & $(0.1 \%$ to $0.9 \%)$ & 0.1 & $(0.0 \%$ to $0.8 \%)$ & 1169 & 1397 & 775 & 1367 \\
\hline $45-54$ & 0.8 & $(0.4 \%$ to $1.5 \%)$ & 0.0 & & 1058 & 1365 & 745 & 1336 \\
\hline $55-64$ & 0.8 & $(0.4 \%$ to $1.7 \%)$ & 0.0 & & 969 & 1169 & 692 & 1085 \\
\hline $65-74$ & 0.7 & (0.3\% to $1.7 \%)$ & 0.0 & & 787 & 843 & 581 & 758 \\
\hline Total aged 16-44 & 0.2 & (0.1\% to $0.4 \%)$ & 0.1 & $(0.0 \%$ to $0.3 \%)$ & 5257 & 3662 & 3569 & 3639 \\
\hline Total aged $45-74$ & 0.8 & $(0.5 \%$ to $1.2 \%)$ & 0.0 & & 2814 & 3377 & 2018 & 3180 \\
\hline Total & 0.5 & $(0.3 \%$ to $0.7 \%)$ & 0.0 & $(0.0 \%$ to $0.2 \%)$ & 8071 & 7040 & 5587 & 6818 \\
\hline \multicolumn{9}{|l|}{ Past 5 years } \\
\hline $16-24$ & 0.1 & $(0.0 \%$ to $0.4 \%)$ & 0.1 & $(0.0 \%$ to $0.8 \%)$ & 1726 & 962 & 1363 & 990 \\
\hline $25-34$ & 0.1 & $(0.0 \%$ to $0.4 \%)$ & 0.1 & $(0.0 \%$ to $0.4 \%)$ & 2362 & 1304 & 1431 & 1281 \\
\hline $35-44$ & 0.0 & $0.0 \%$ & 0.0 & $0.0 \%$ & 1169 & 1397 & 775 & 1367 \\
\hline $45-54$ & 0.0 & $0.0 \%$ & 0.0 & $0.0 \%$ & 1058 & 1365 & 745 & 1336 \\
\hline $55-64$ & 0.0 & $0.0 \%$ & 0.0 & $0.0 \%$ & 969 & 1169 & 692 & 1085 \\
\hline $65-74$ & 0.0 & $0.0 \%$ & 0.0 & $0.0 \%$ & 787 & 843 & 581 & 758 \\
\hline Total aged 16-44 & 0.1 & $(0.0 \%$ to $0.2 \%)$ & 0.0 & $(0.0 \%$ to $0.2 \%)$ & 5257 & 3662 & 3569 & 3639 \\
\hline Total aged 45-74 & 0.0 & & 0.0 & & 2814 & 3377 & 2018 & 3180 \\
\hline Total & 0.0 & $(0.0 \%$ to $0.1 \%)$ & 0.0 & $(0.0 \%$ to $0.1 \%)$ & 8071 & 7040 & 5587 & 6818 \\
\hline
\end{tabular}

not possible, and underrepresentation of these groups might also have led to underestimation of prevalence.

Worldwide data sets providing robust estimates of T. vaginalis prevalence in the general population are limited to the USA. The 2001-2002 Add Health study found the prevalence in women aged $18-26$ years was $2.8 \%(2.2 \%$ to $3.6 \%){ }^{\text {w5 }}$ The 2001-2004 NHANES study reported that the prevalence in women aged $14-49$ years was $3.1 \%$ (2.2\% to $4.3 \%)$, driven by very high prevalence in women of non-Hispanic black ethnicity (13.3\% (10.0-17.7). ${ }^{\mathrm{w} 6}$ A probability sample of young adults undertaken in Baltimore in 2006-2009 reported that prevalence was $4.1 \%(2.3 \%$ to $7.0 \%)$ in non-black women and $16.6 \%$ $(13.0 \%$ to $19.8 \%)$ in women of black ethnicity. ${ }^{\text {w7 }}$ The use of different samples and assays in these studies complicates comparison, but it is striking that the US data consistently show much higher prevalence estimates than we found in Britain. Differences in the demographic composition of the USA and British populations might partially account for these findings, but we note that prevalence estimates in black women in the Natsal sample are also lower, which might be explained by differences in access to healthcare. Overall higher rates of STIs found in black populations might also be due to differences in sexual behaviour (eg, overlapping partnerships and assortative mixing), and associated with underlying social factors such as deprivation. $^{\text {w8 }}$

These data are timely because molecular assays to detect T. vaginalis are now commercially available, increasing the feasibility of widespread screening, including outside of specialist sexual health services. However, given the very low prevalence detected, unselected screening of asymptomatic individuals is unlikely to represent a cost-effective use of resources. Instead, these data support policies that focus the deployment of molecular tests within clinical settings where pilot studies and/or demography provide evidence of higher prevalence in the local community. It is now the role of professional clinical and public health organisations to take these findings, together with other published evidence, to make recommendations about $T$. vaginalis screening and diagnostic testing.

\section{Ethical approval}

We obtained ethics approval from Oxfordshire Research Ethics Committee A (reference 09/H0604/27). Participants gave written informed consent to anonymised testing, without the return of results, the ethical rationale for which has been previously described. ${ }^{\text {w9 }}$ A substantial amendment was subsequently approved by Oxfordshire Research Ethics Committee to test for T. vaginalis where participants had provided consent to any remaining urine being stored for studies investigating diseases in the population.

\section{Handling editor Jackie A Cassell}

Twitter Follow Nigel Field at @fienige and Sarah Alexander at @sarah1alexander

Acknowledgements Natsal-3 is a collaboration between University College London (London, UK), the London School of Hygiene and Tropical Medicine

(London, UK), NatCen Social Research, Public Health England (formerly the Health Protection Agency) and the University of Manchester (Manchester, UK). We thank the study participants, the team of interviewers from NatCen Social Research and operations and computing staff from NatCen Social Research; Chinelo Obi, Rebecca Howell-Jones, David Mesher, Heather Northend, Krishna Gupta and Tracey Cairns (Department of HIV and Sexually Transmitted Infections, Public Health England) for data linkage, anonymisation and data entry; Pamela Saunders (Sexually Transmitted Bacteria Reference Unit, Public Health England) and Filomeno Coelho da Silva (Virus Reference Department, Public Health England) for their contributions to development of protocols and testing; and Holly Mitchell (Department of HIV and Sexually Transmitted Infections, Public Health England) for sharing raw data from her paper on English rates of $T$. vaginalis.

Contributors NF, SA, CAI and PS conceived this article. NF wrote the first draft with further contributions from SC, SA, CAI, GH, LH, SB, CHM, CT, AMJ and PS. $\mathrm{LH}$ did the literature review. SC did the statistical analysis. PS, CAI, CHM and AMJ, initial applicants on Natsal-3, wrote the study protocol and obtained funding. PS, CHM, CAl, AMJ, SC, CT and NF designed the Natsal-3 questionnaire, applied for ethics approval and undertook piloting of the questionnaire. SC and CM managed 
data. SA, RK and PS were responsible for laboratory testing. All authors interpreted data, reviewed successive drafts and approved the final version of the article.

Funding The study was supported by grants from the Medical Research Council (G0701757) and the Wellcome Trust (084840), with contributions from the Economic and Social Research Council and Department of Health.

Competing interests None declared.

Ethics approval Oxfordshire Research Ethics Committee A.

Provenance and peer review Not commissioned; externally peer reviewed.

Data sharing statement An anonymised Natsa-3 data set has been deposited with the UK Data Service, persistent identified: 10.5255/UKDA-SN-7799-1. Researchers are also directed to the Natsal website for further information (http:// www.natsal.ac.uk).

Open Access This is an Open Access article distributed in accordance with the terms of the Creative Commons Attribution (CC BY 4.0) license, which permits others to distribute, remix, adapt and build upon this work, for commercial use, provided the original work is properly cited. See: http://creativecommons.org/licenses/ by/4.0/

\section{REFERENCES}

1 World Health Organization. Global incidence and prevalence of selected curable sexually transmitted infections-2008. 2012. http://apps.who.int/iris/bitstream/ 10665/75181/1/9789241503839_eng.pdf
2 Mitchell HD, Lewis DA, Marsh K, et al. Distribution and risk factors of Trichomonas vaginalis infection in England: an epidemiological study using electronic health records from sexually transmitted infection clinics, 2009-2011. Epidemiol Infect 2014;142:1678-87.

3 Public Health England. Sexually transmitted infections and chlamydia screening in England, 2014. Health Prot Rep 2015;9. https://www.gov.uk/government/uploads/ system/uploads/attachment_data/file/437433/hpr2215_STI_NCSP_v6.pdf

4 Sherrard J, Ison C, Moody J, et al. United Kingdom National Guideline on the Management of Trichomonas vaginalis 2014. Int J STD AIDS 2014;25:541-9.

5 Sonnenberg $\mathrm{P}$, Clifton $\mathrm{S}$, Beddows $\mathrm{S}$, et al. Prevalence, risk factors, and uptake of interventions for sexually transmitted infections in Britain: findings from The National Surveys of Sexual Attitudes and Lifestyles (Natsal). Lancet 2013:382:1795-806.

6 Erens B, Phelps A, Clifton S. The third National Survey of Sexual Attitudes and Lifestyles (Natsal-3): Technical report. National Centre for Social Research, 2013.

7 Erens B, Phelps A, Clifton S, et al. Methodology of the third British National Survey of Sexual Attitudes and Lifestyles (Natsal-3). Sex Transm Infect 2014;90:84-9.

8 Kengne P, Veas F, Vidal N, et al. Trichomonas vaginalis: repeated DNA target for highly sensitive and specific polymerase chain reaction diagnosis. Cell Mol Biol (Noisy-le-grand) 1994;40:819-31.

9 Pillay A, Radebe F, Fehler G, et al. Comparison of a TaqMan-based real-time polymerase chain reaction with conventional tests for the detection of Trichomonas vaginalis. Sex Transm Infect 2007;83:126-9.

10 Madico G, Quinn TC, Rompalo A, et al. Diagnosis of Trichomonas vaginalis infection by PCR using vaginal swab samples. J Clin Microbiol 1998;36:3205-10. 